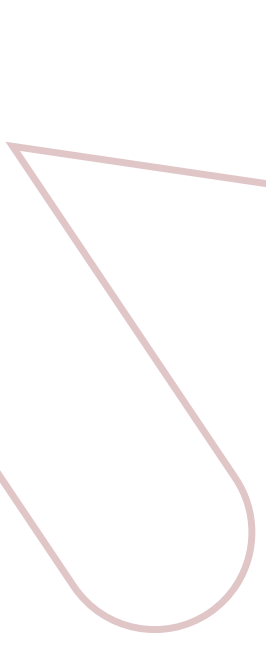

\title{
A inserção do design universal e disciplinas correlacionadas nas instituições de ensino superior em design no Brasil: um panorama geral obtido por meio dos sites institucionais
}

The insertion of universal design and correlated disciplines in higher education institutions in design in Brazil: an overview collected through institutional websites

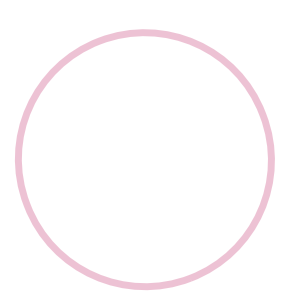

\section{Bruna da Silveira Suris}

Centro Universitário Ritter dos Reis

bruna_suris@hotmail.com $\mathbf{x}$

Heli Meurer

Centro Universitário Ritter dos Reis

heli.meurer@gmail.com $\mathbf{x}$

Vinícius Gadis Ribeiro

Centro Universitário Ritter dos Reis

vinicius@uniritter.edu.br

DI

PROJËTICA

\section{COMO CITAR ESTE ARTIGO:}

SURIS, Bruna da Silveira; MEURER, Heli; RIBEIRO, Vinícius Gadis. A inserção do design universal e disciplinas correlacionadas nas instituições de ensino superior em design no brasil: um panorama geral obtido por meio dos sites institucionais. Projética, Londrina, v. 12, n. 1, p. 143-167, 2021

DOI: 10.5433/2236-2207.2021v12n1p143

Submissão: 01-10-2017

Aceite: $22-02-2020$ 
RESUMO: Este artigo tem como objetivo analisar as matrizes curriculares das Instituições de Ensino Superior em Design (IES) no Brasil, a partir de uma pesquisa qualitativa de caráter descritivo e com procedimento técnico de análise sistemática. Foram analisadas 140 IES por meio dos sites, quanto à matriz curricular, ementa e linhas de pesquisa de pós-graduação. A execução consistiu na investigação em base de dados e no uso de critérios para se chegar a uma amostragem final.

Palavras-chave: Educação. Instituições de ensino superior em design. Matriz curricular. Design universal. Ergonomia.

ABSTRACT: This article aims to analyze the curricula of higher education institutions in design in Brazil, based on a qualitative research with a descriptive nature and a technical procedure of systematic analysis. 140 higher education institutions were analyzed through their websites, regarding the curricula, syllabi and graduate research lines. The conduction consisted of database research and the use of criteria to come to a final sampling.

Keywords: Education. Higher education institutions in design. Curriculum. Universal design. Ergonomics.

\section{INTRODUÇÃO}

A questão da inclusão social tornou-se desafiadora para as organizações empresariais e também para as Instituições de Ensino Superior (IES) nos últimos anos. É um tema de importância social que está em crescimento nos últimos anos, a partir, da Convenção da ONU sobre o Direito das Pessoas com Deficiências de 2008, que serviu de base para a Lei 13.146/15 - Lei Brasileira da Inclusão, que foi 
sancionada no ano de 2015. Consequentemente, suas operações estão sujeitas a pressões e análises de uma diversa gama de interessados dentro e fora das organizações e das IES, como prefeituras, agências do governo, a justiça, os estudantes, as pessoas com deficiências e seus familiares, entre outros. Diante do exposto, percebe-se que tais desafios e imposições, podem servir de ponto de partida, para que as IES comecem a considerar com muita seriedade a possibilidade de incentivar um aumento significativo na produção de pesquisas acadêmica e científicas na área da inclusão social.

A Lei 13.146/15 (Lei Brasileira da Inclusão) determina no Art. 77 que o poder público deve fomentar o desenvolvimento científico, a pesquisa, a inovação e a capacitação tecnológica, voltada à melhoria da qualidade de vida e ao trabalho da pessoa com deficiência e sua inclusão social e também propõe no $\S 2^{\circ}$ que a acessibilidade e as tecnologias assistivas e sociais devem ser fomentadas mediante a criação de cursos de pós-graduação, a formação de recursos humanos e a inclusão do tema nas diretrizes de áreas do conhecimento.

Esta pesquisa tem por objetivo caracterizar as matrizes curriculares das IES em Design no Brasil, em cursos superiores de Tecnologia e Graduação no âmbito do Design Universal e disciplinas correlacionadas, com o intuito de identificar o ensino e aprendizagem na área. Também se realizou um levantamento com relação dos cursos de Pós-graduação Lato Sensu e Stricto Sensu, para fins de investigar se há e quais são as linhas de pesquisa voltadas para a temática deste estudo. O assunto desta pesquisa de forma geral é o Design, o tema é o Ensino de Design no Brasil sob o enfoque do Design Universal e disciplinas correlacionadas. O problema de pesquisa é "Como caracterizar o Ensino de Design a partir de matrizes curriculares e linhas de pesquisa propostas pelas IES em Design no Brasil no ano de 2012?".

Assim, deseja-se fomentar pesquisas sobre o tema e proporcionar um artigo que indique a importância da inserção do Design Universal, na grade curricular ou em atividades complementares/extensão dos cursos superiores de Design no Brasil, tornando-o ator principal na integração dos estudantes de Design e a inclusão social, mitigando a percepção de diferenciação e necessidades das 
pessoas com deficiências. Dentro desta lógica realizou-se uma análise sistemática para coleta de dados, onde, selecionou-se através do ENADE 2012 as IES em Design e analisou-se suas habilitações, matrizes curriculares, ementas, linhas de pesquisa, entre outros. Posteriormente, foram feitas análises dos dados obtidos na busca nos sites institucionais.

Este artigo está estruturado da seguinte forma: Introdução; Referencial Teórico, com o ensino de Design no Brasil, o estudo da Lei Brasileira da Inclusão, Acessibilidade, Design Universal e Tecnologia Assistiva; Metodologia, com a apresentação das ferramentas utilizadas para o desenvolvimento da pesquisa; Resultados Obtidos, onde serão apresentados os dados que foram encontrados no presente estudo; por fim, as Considerações Finais com o fechamento do artigo.

\section{REFERENCIAL TEÓRICO}

A presente sessão divide-se em subseções, sendo elas: o Ensino de Design no Brasil; Conceituação da LBI e demais terminologias; a partir de referências bibliográficas de cada área específica.

\subsection{O Ensino do Design no Brasil}

Conforme Couto (2008), o marco simbólico que deu início ao ensino em Design no Brasil foi à criação da Escola Superior de Desenho Industrial - ESDI no Rio de Janeiro em 1963. No currículo proposto pela ESDI no $2^{\circ}$ ano letivo já havia na matriz curricular a disciplina de Ergologia I e no $3^{\circ}$ ano Ergologia II, com isso, pode-se perceber que questões de promoção e proteção da saúde do indivíduo já eram temas pensados nos cursos de Design da época. Após processo de reflexão da ESDI, em 1968 elaborou-se um novo currículo que foi aceito pelo Conselho Federal de Educação - como o primeiro currículo base para cursos de Design no país. Neste currículo a disciplina de Ergonomia pertencia a matriz curricular tanto da Habilitação em Projeto de Produto quanto em Programação Visual. 
O currículo mínimo para cursos de Design, só foi oficializado pelo Conselho Federal de Educação em 1987, mas o mesmo já havia sido elaborado desde 1978. Já em 2003 as novas Diretrizes Curriculares Nacionais trouxeram para as Instituições de Ensino Superior a independência na composição de carga horária dos currículos. Assim, através do Parecer CES/CNE 0195 de 2003 e publicado em 2004 no Diário Oficial da União, apresentou-se às diretrizes, agora específicas, para os cursos de bacharelado em Design. Com isso, pode-se perceber a enorme batalha que docentes e pesquisadores tem enfrentado para atualizar currículos, inserir novas disciplinas e propiciar discussões sobre temáticas atuais. A partir da vigência das Diretrizes Curriculares pode-se pensar no campo de Design e no papel do estudante de Design como fruto de um pensamento de relação sistêmica global que inseri o meio, a subjetividade e a visão de forma coletiva. (COUTO, 2008).

Assim, realizou-se uma pesquisa sobre a Lei da Inclusão da Pessoa com Deficiência no Brasil e também sobre termos utilizados para a aplicação da Lei, sendo eles: Acessibilidade, Design Universal e Tecnologia Assistiva.

\subsection{Lei Brasileira da Inclusão da Pessoa com De iciência}

Conforme o Guia sobre a Lei Brasileira da Inclusão a Lei Brasileira de Inclusão da Pessoa com Deficiência (Estatuto da Pessoa com Deficiência) - LBI 13.146, foi sancionada no dia 06 de julho do ano de 2015, após 15 anos em tramitação (GUIA..., 2015). A trajetória da LBI se deu da seguinte forma: no ano de 2000 o texto da Lei Brasileira da Inclusão foi apresentado pela primeira vez pelo deputado Paulo Paim e em 2003 a proposta com teor idêntico, pelo então Senador Paulo Paim, foi apresentada ao Senado. Houveram outras etapas, até que em 2008, foi ratificada

a Convenção da ONU sobre o Direito das Pessoas com Deficiências, já entre 2013 a 2014 ocorreram consultas e audiências públicas abertas que recolheram sugestões da população de todo o Brasil. No próprio ano de 2014 foi apresentado o texto final da LBI pela relatora Mara Gabrilli. Em 2015 houve a aprovação do texto substitutivo 
na Câmara dos Deputados e aprovação do texto no Senado, relatado pelo senador Romário, até que por fim ocorreu a sanção do projeto pela então Presidente Dilma Rousseff.

A LBI é destinada a assegurar e a promover, em condições de igualdade, o exercício dos direitos e das liberdades fundamentais por pessoa com deficiência, visando à sua inclusão social e cidadania. O texto da LBI tem como base fundamental a Convenção da ONU sobre os Direitos das Pessoas com Deficiência, sendo, o primeiro tratado internacional de direitos humanos a ser incorporado pelo ordenamento jurídico brasileiro como emenda constitucional. No Brasil, a LBI, baseou-se na carência de serviços públicos existentes, nas demandas da população como um todo. A sua composição partiu-se do pressuposto, no qual, nenhum retrocesso sobre os direitos até então conquistados, poderia ser feito. (GUIA ..., 2015).

No Título IV - DA CIÊNCIA E TECNOLOGIA - no Art. 77. Definiu-se que o poder público deve fomentar o desenvolvimento científico, a pesquisa, a inovação e a capacitação tecnológica, voltada à melhoria da qualidade de vida e ao trabalho da pessoa com deficiência e sua inclusão social (GUIA..., 2015).

$\S 1^{\circ} \mathrm{O}$ fomento pelo poder público deve priorizar a geração de conhecimentos e técnicas que visem à prevenção e ao tratamento de deficiências e ao desenvolvimento de tecnologias assistiva e social.

$\S 2^{\circ} \mathrm{A}$ acessibilidade e as tecnologias assistiva e social devem ser fomentadas mediante a criação de cursos de pós-graduação, a formação de recursos humanos e a inclusão do tema nas diretrizes de áreas do conhecimento. $\S 3^{\circ}$ Deve ser fomentada a capacitação tecnológica de instituições públicas e privadas para o desenvolvimento de tecnologias assistiva e social que sejam voltadas para melhoria da funcionalidade e da participação social da pessoa com deficiência.

$\S 4^{\circ}$ As medidas previstas neste artigo devem ser reavaliadas periodicamente pelo poder público, com vistas ao seu aperfeiçoamento. 
$\mathrm{Na}$ LBI em seu Art. $3^{\circ}$ Para fins de aplicação da Lei, consideram-se alguns termos da seguinte maneira:

I Acessibilidade: possibilidade e condição de alcance para utilização, com segurança e autonomia, de espaços, mobiliários, equipamentos urbanos, edificações, transportes, informação e comunicação, inclusive seus sistemas e tecnologias, bem como de outros serviços e instalações abertos ao público, de uso público ou privados de uso coletivo, tanto na zona urbana como na rural, por pessoa com deficiência ou com mobilidade reduzida;

Il Desenho universal: concepção de produtos, ambientes, programas e serviços a serem usados por todas as pessoas, sem necessidade de adaptação ou de projeto específico, incluindo os recursos de tecnologia assistiva;

III Tecnologia assistiva ou ajuda técnica: produtos, equipamentos, dispositivos, recursos, metodologias, estratégias, práticas e serviços que objetivem promover a funcionalidade, relacionada à atividade e à participação da pessoa com deficiência ou com mobilidade reduzida, visando à sua autonomia, independência, qualidade de vida e inclusão social. (GUIA..., 2015).

\subsection{Acessibilidade}

Dessa forma, buscou-se entender o conceito dos termos Acessibilidade, Desenho Universal e Tecnologia Assistiva para complementar a definição da LBI e relacionálos ao Design. Assim, o termo acessibilidade define que toda pessoa portadora de deficiências e/ou mobilidade reduzida tenha possibilidade e condições, com segurança e autonomia, de utilizar espaços mobiliários, urbanos, de edificações, de transportes e de sistemas de comunicação. (BRASIL, 2000; LAMÔNICA et al., 2008). Em decorrência da legislação brasileira, toda pessoa, incluindo as que apresentam deficiências, devem ter acesso garantido, no que diz respeito à educação, à saúde, 
ao lazer e também ao trabalho. Andrade, Pacheco e Farias (2007) corroboram com essa afirmação, pois, descrevem que os indivíduos devem ser percebidos com igualdade e com isso, devem receber atendimento e reconhecimento das suas específicas necessidades.

Conforme Lamônica et al. (2008), ao serem assegurados por lei, as pessoas com deficiências têm seus direitos e os mesmos necessitam ser respeitados, pois, a acessibilidade defende o conceito de cidadania. Porém, conforme, Bittencourt et al. (2004) as barreiras sociais e também as arquitetônicas dificultam esses direitos, pois, somente um espaço construído acessível a todos pode proporcionar oportunidades iguais aos seus usuários. Assim, refletir sobre as barreiras físicas que causam dificuldades aos deficientes são de extrema importância, porque, propõe o repensar de práticas e propostas de ações que podem melhorar a qualidade de vida e promover a saúde destas pessoas.

\subsection{Design Universal}

Já o conceito de Design Universal teve início em 1987, com o arquiteto norteamericano Ron Mace, que se dedicou à questão da acessibilidade e necessitava de cadeira de rodas e um respirador artificial para viver. O termo tem crescido e com isso, gerado interesse, entre profissionais como designers, engenheiros, arquitetos, paisagistas, entre outros. O Design Universal tem sido aplicado em projetos de ambientes públicos, edifícios e produtos, sempre com o objetivo de produzir artefatos ou serviços, dos quais, a grande maioria das pessoas possa fazer uso. A sua aplicação está diretamente ligada com uma sociedade inclusiva, pois não é apenas uma tecnologia focada aos que dela necessitam e sim um design para todas as pessoas. E até mesmo questões de preocupações ambientais estão envolvidas, pois, o profissional que faz uso do Design Universal evita a necessidade de ambientes e produtos específicos para pessoas com deficiências, de forma a assegurar que todos possam usar de forma segura e autônoma os espaços e objetos desenvolvidos. (CARLETTO; CAMBIAGHI, 2008). 
Segundo Carletto e Cambiaghi (2008) em 1997 foram desenvolvidos os Sete Princípios do Design Universal por peritos do Centro de Desenho Universal da Universidade da Carolina do Norte, tendo como foco a concepção, no maior nível possível, de produtos e ambientes utilizáveis por todos os indivíduos sem necessidade de adaptações. O projeto universal pode ser aplicado tanto na avaliação de artefatos que já foram desenvolvidos, como servir de orientação para a criação de produtos e ambientes novos (IIDA, 2005).

Conforme lida (2005) os sete princípios adotados no Design Universal são: Uso Equitativo, ser útil para pessoas com as mais diversas capacidades; Flexibilidade no uso, acomodar um grande leque de capacidades e preferências individuais; Uso Simples \& Intuitivo, utilização dos produtos e ambientes ser facilmente entendida, independente, da experiência de uso; Informação Perceptível, comunicação de o produto ser eficaz; Tolerância ao erro, reduzir ao máximo os riscos e consequências adversas das ações dos usuários; Redução do Gasto Energético, uso dos artefatos de forma eficiente e confortável causando pouca fadiga; Espaço Apropriado, proporcionar tamanho e espaço apropriado ao uso independente do corpo, postura ou limitação do usuário.

\subsection{Tecnologia Assistiva}

Diferente do Design Universal, a Tecnologia Assistiva tem foco no desenvolvimento de projetos direcionados principalmente para crianças e/ou adultos com deficiências e/ou limitações. A Tecnologia Assistiva é um termo bastante recente, que tem como objetivo propiciar à criança ou adulto com deficiência e/ou limitações, recursos e serviços que proporcionem uma maior qualidade de vida, que atendam às suas respectivas necessidades e que ao mesmo tempo auxiliem na reabilitação do deficiente, tornando-se uma grande aliada, para os profissionais da saúde, através de produtos e recursos disponibilizados, que foram projetados especificamente para esse público. Assim, promover uma vida com independência e inclusão na sociedade é a prioridade. (SARTORETTO; BERSCH, 2014). 


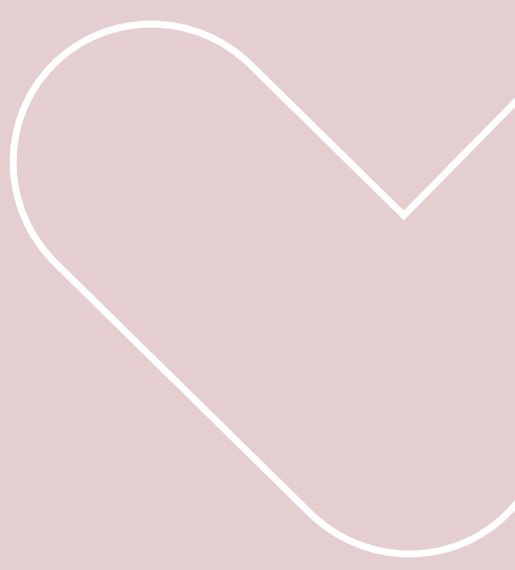

No Título IV - DA CIÊNCIA E TECNOLOGIA - no Art.

77. Definiu-se que o poder público deve fomentar o desenvolvimento científico, a pesquisa, a inovação e a capacitação tecnológica, voltada à melhoria da qualidade de vida e ao trabalho da pessoa com deficiência e sua inclusão social (GUIA..., 2015). 
Citando o conceito do ADA - American with Disabilities Act, Tecnologia Assistiva refere-se a "uma ampla gama de equipamentos, serviços, estratégias e práticas concebidas e aplicadas para minimizar os problemas funcionais encontrados pelos indivíduos com deficiências". É uma área voltada totalmente para o usuário e não um recurso do profissional ou de algum campo de trabalho de atuação específica e está diretamente interligada em diversas outras áreas, tornando-se um tema transdisciplinar, envolvendo profissionais como educadores, engenheiros, arquitetos, designers, terapeutas ocupacionais, fonoaudiólogos, fisioterapeutas, médicos, assistentes sociais, psicólogos, entre outros. A acessibilidade também envolve equipe multidisciplinar e diz respeito às condições de autonomia. (COOK; HUSSEY, 1995).

\section{METODOLOGIA}

O presente trabalho tem como objetivo principal obter o panorama geral das IES em Design no Brasil e suas matrizes curriculares, ementas e linhas de pesquisa, nas quais há aplicação dos termos Design Universal e de suas áreas afins, como a Ergonomia, Acessibilidade, Usabilidade, entre outros. Assim, foram investigados os sites institucionais de 140 IES em Design que participaram do ENADE 2012.

No que diz respeito à metodologia científica é válido destacar a sua relevância para os estudos acadêmicos. Dessa maneira, pesquisou-se que termo Metodologia surgiu do grego "meta" (ao largo); "odos" (caminho); "logos" (discurso, estudo). A Metodologia consiste, portanto, em examinar os métodos e técnicas de pesquisa para desenvolver uma pesquisa acadêmica, é um caminho que devemos empregar, através de etapas como a coleta e processamento de informações, adquiridas ao longo da investigação, com o intuito de se chegar a um resultado e comprovar sua validade, ou seja, é uma linha de raciocínio para se alcançar o conhecimento. (PRODANOV; FREITAS, 2013).

Com relação à pesquisa, pode-se afirmar que seu objetivo é através do uso de métodos científicos, resolver problemáticas e solucionar dúvidas. Quanto à pesquisa científica tem-se um estudo planejado, onde a característica do aspecto científico da investigação é o método de abordagem do problema. Assim, através 
da pesquisa científica há possibilidade de solucionar questões por meio do uso de métodos científico. (PRODANOV; FREITAS, 2013).

O presente estudo realizou uma pesquisa qualitativa, pois traduz em números as informações obtidas, classificando-as e analisando-as. Utilizou-se o método de caráter descritivo, que segundo Prodanov e Freitas (2013) propicia ao pesquisador descrever os fatos sem a ocorrência de interferências e propõe-se a entender as características de um determinado objeto, por meio de observação, registro, análise, classificação e interpretação de dados sem manipulá-los.

O procedimento técnico adotado com relação ao método de pesquisa é análise sistemática ou revisão sistemática. Para Sampaio e Mancini (2007), análise sistemática trata-se de uma investigação específica que ao final disponibiliza dados sobre evidências que tenham relação ao objeto de estudo, mediante aplicação de métodos sistematizados de busca, apreciação e síntese da informação encontrada. Esse tipo de análise identifica temas que carecem de evidência e servem de base orientadora para investigações futuras.

Para o método da análise sistemática e com o intuito de entrar em contato com os dados coletados na internet, sem preocupações dos mesmos serem confiáveis e fiéis, teve-se o cuidado de obter informações derivadas do Governo, através do ENADE. Segundo o site do (INEP)-Instituto Nacional de Estudos e Pesquisas Educacionais Anísio Teixeira (2011), o (ENADE) - Exame Nacional de Desempenho de Estudantes, tem por objetivo avaliar o desempenho e rendimento de estudantes de cursos de graduação, quanto aos conteúdos programáticos constituídos nas diretrizes curriculares adquiridas em sua formação. A periodicidade máxima da avaliação é trienal para cada área do conhecimento, assim a amostra analisada foi do ano de 2012 (dados completos disponíveis na internet), houve ENADE para a área de Design em 2015, porém as informações não estão integralmente disponíveis, impedindo a obtenção dos dados para esta pesquisa.

Os critérios de avaliação para a coleta de dados foram a exclusão das IES que participaram do ENADE 2012, mas que não contavam com cursos na área do Design em seus sites institucionais; IES que obtinham cursos na área do Design, mas que não se enquadravam em bacharelado e tecnólogo; IES que tinham cursos livres na área do Design, mas não especificamente um curso de graduação ou tecnologia; por fim, não se contabilizou as IES que possuíam apenas cursos de Design a distância. 
Para a realização da análise foram desenvolvidas 3 etapas. Na primeira foi realizado o download de um arquivo que continha os dados das IES em Design, derivados do ENADE 2012, na qual, os mesmos foram exportados para uma planilha onde havia as seguintes colunas: Instituição, categoria administrativa (pública ou privada), organização acadêmica (universidade, centro universitário ou faculdade), município e estado. Na segunda etapa, foi elaborada uma nova planilha, baseada nos dados da anterior, com as seguintes colunas: Instituição, coordenação de curso, habilitações (curso), nível de ensino (bacharelado ou tecnólogo), disciplina, ementa, acesso dia/mês, Mestrado, Doutorado e Especialização. Na terceira etapa, foram as planilhas foram completas com as informações obtidas nos sites institucionais das IES em Design e posteriormente, criaram-se tabelas e gráficos indicando os resultados obtidos na presente pesquisa, como forma de melhor visualização dos dados gerados.

\section{RESULTADOS OBTIDOS}

O presente estudo foi realizado através de 3 etapas, onde, ao analisar as IES em Design no Brasil, que participaram no ano de 2012 no ENADE, identificou-se um total de 140 IES em Design no Brasil. Para fins de identificação do volume de IES em Design por Estados no Brasil, realizou-se um levantamento, conforme Gráfico 1. Nota-se que o Estado brasileiro com maior número de cursos de Design é São Paulo com 36, seguido de Santa Catarina com 20, Rio Grande do Sul com 18, Paraná com 12, Minas Gerais com 12, Rio de Janeiro com 11, entre outros.

Com relação à organização acadêmica das IES em Design que participaram do ENADE 2012, pode-se afirmar que 50\% são Universidades (70 sobre o total de 140), 34\% são Faculdades (47 sobre o total de 140) e 16\% são Centros Universitários (23 sobre o total de 140). No que diz respeito à categoria administrativa das IES em Design que participaram do ENADE 2012, pode-se afirmar que 105 delas são privadas e 35 são públicas. 
Gráfico 1 - Volume de IES em Design nos Estados Brasileiros.

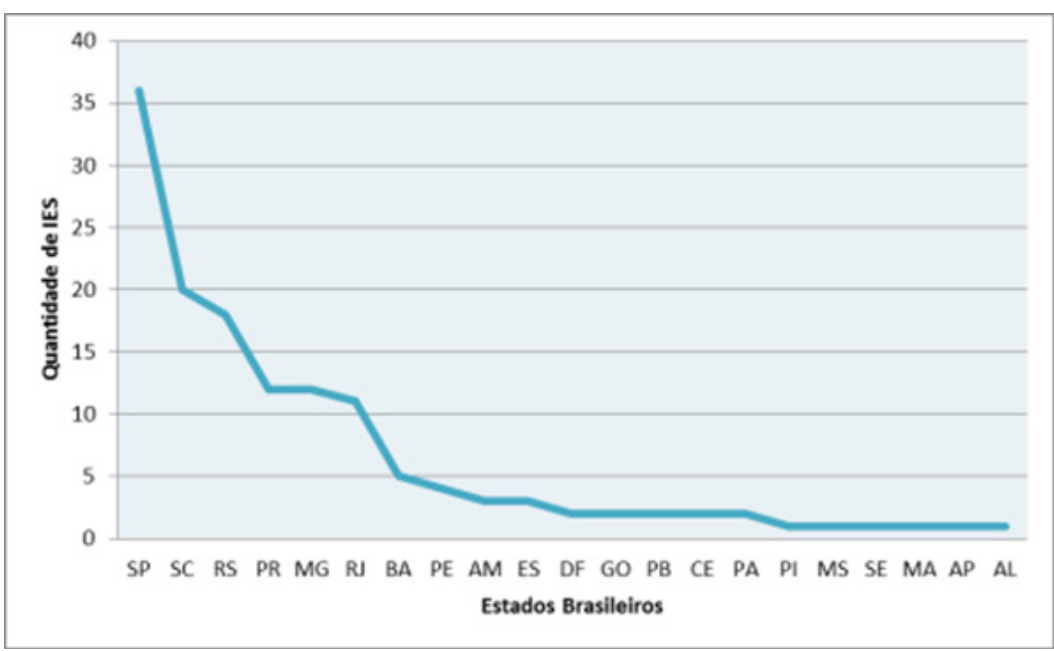

Fonte: Elaborado pelo autor, com base na pesquisa realizada.

Gráfico 2 - Cursos de Bacharelado em Design nas IES.

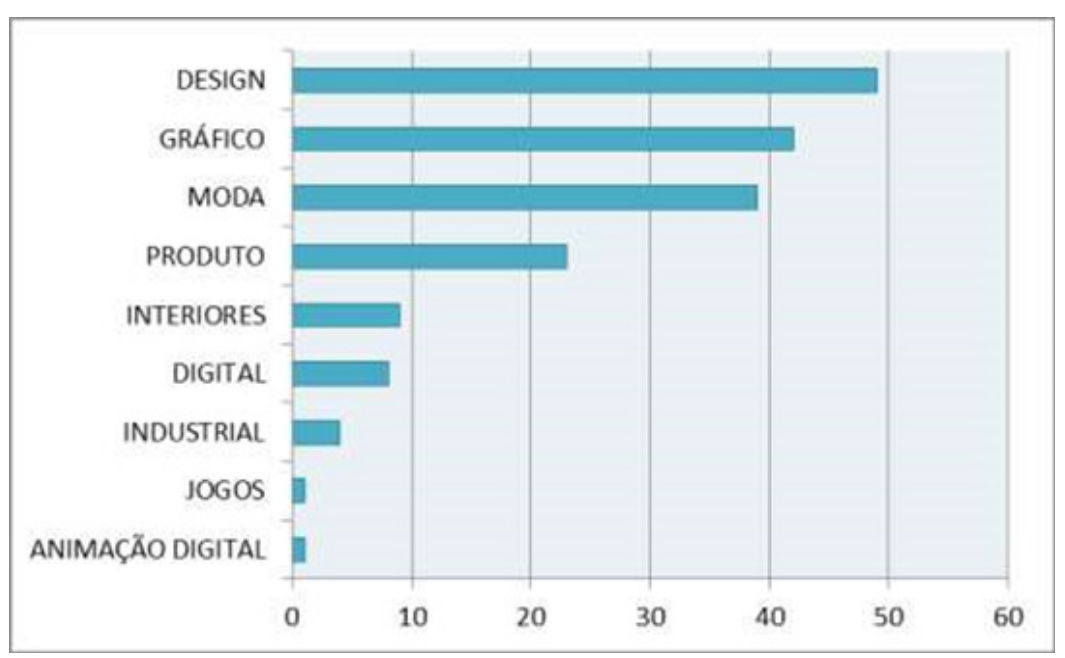

Fonte: Elaborado pelo autor, com base na pesquisa realizada. 
Através da busca nos sites institucionais das IES em Design, com auxílio da segunda planilha elaborada, identificou-se e explorou-se uma vasta gama de dados. Contabilizaram-se ao final 130 IES em Design no Brasil, após aplicação dos critérios de exclusão mencionados no item 3 Metodologia. Cada IES tem um volume específico de cursos na área do Design, podendo ser Bacharelado ou Tecnólogo.

Sendo assim, totalizaram-se nesta análise, 222 cursos de Design, onde, 176 são bacharelados e 59 são Tecnólogos. O Gráfico 2 indica os principais cursos de Bacharelado das IES, no qual, o curso de Design aparece 49 vezes, seguido de Design Gráfico com 42, Moda com 39, Design de Produto com 23, Design de Interiores com 9, Design Digital com 8, Design Industrial com 4, Design de Jogos com 1, seguido de Animação Digital.

No Gráfico 3, verifica-se que os cursos Tecnólogos nas IES em Design com base no ENADE 2012 são: Design de Interiores com 23, Moda com 16, Design Gráfico com 12, Design de Produto com 4, Animação Digital com 2, por fim, Jogos e Design com 1.

Gráfico 3 - Cursos Tecnólogos em Design nas IES.

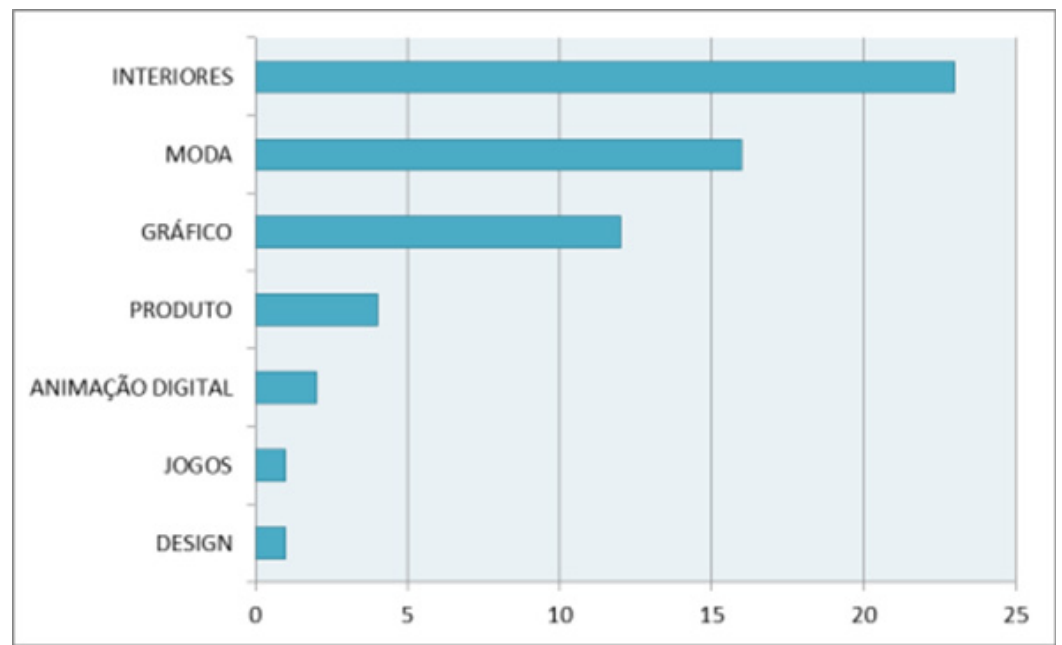

Fonte: Elaborado pelo autor, com base na pesquisa realizada. 
Depois de coletados os dados gerais das IES em Design, realizou-se uma série análises com relação às questões das matrizes curriculares dos cursos de Design. Assim, através da planilha elaborada e das buscas nos sites institucionais, identificou-se se haviam disciplinas voltadas para a área de interesse deste estudo como ergonomia, design universal, inclusão, design social - nas grades curriculares dos cursos.

Os resultados encontrados foram disciplinas com nomenclaturas diversas que foram categorizadas em 27 termos. No Gráfico 4, pode-se identificar as categorias e a quantidade de vezes em que elas apareceram nos cursos, tanto nos Bacharelados quanto nos Tecnólogos. Essas disciplinas não têm suas ementas disponíveis para acesso nos sites institucionais. Assim, Ergonomia aparece 22 vezes, seguida de Ergonomia Interiores com 14, Ergonomia Moda com 9, Ergonomia Produto com 8, Ergonomia e Design com 7, Ergonomia e Acessibilidade com 5, Ergonomia e Usabilidade com 4, ErgoDesign com 2, Ergonomia no Trabalho/ Produto/Cognitiva com 1, entre outras.

Gráfico 4 - Categorias das Disciplinas nos Cursos de Design sem ementa.

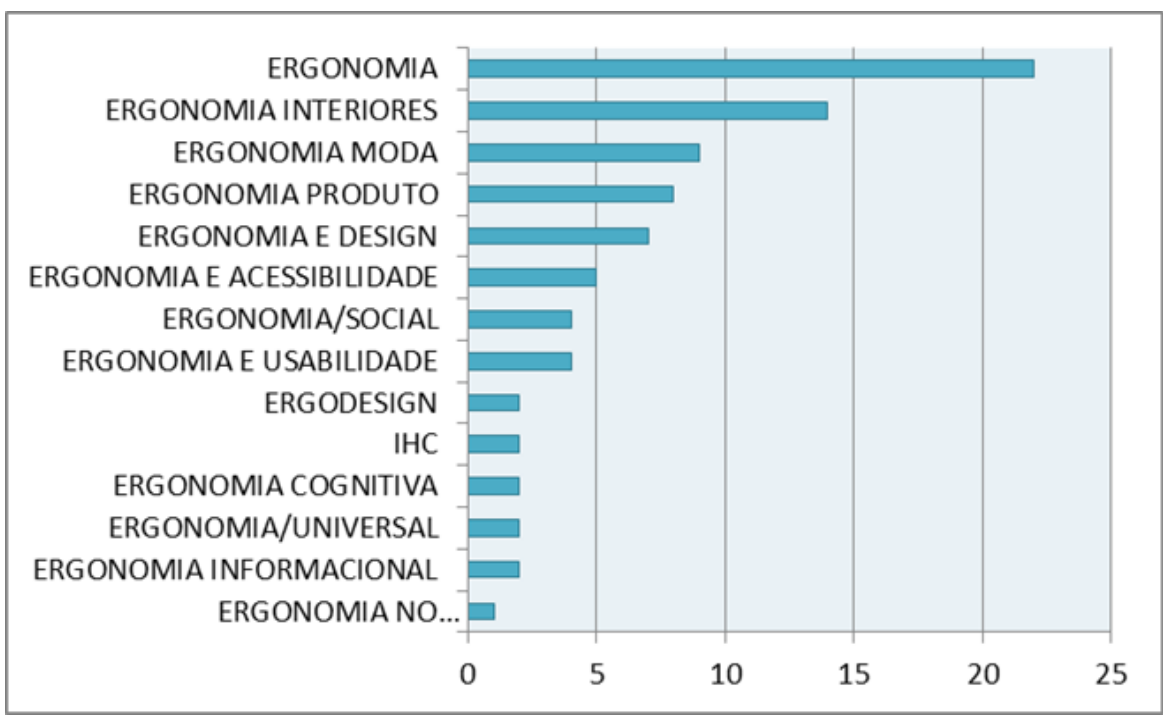

Fonte: Elaborado pelo autor, com base na pesquisa realizada. 
Para fins de uma melhor visualização dos dados, elaborou-se o Gráfico 5, somente com as categorias específicas nas áreas sociais, de inclusão, e universais e de acessibilidade, no qual, totalizaram 7. A categoria Ergonomia e Acessibilidade aparece 5 vezes, seguida de Ergonomia/Social com 4, Ergonomia/Universal com 2, Social/Universal com 1, Ergonomia/Moda/Inclusão/Social com 1, Ergonomia e Design Inclusivo com 1, por fim, Ergonomia/Universal/IHC com 1.

Gráfico 5 - Disciplinas com enfoque Inclusivo nas IES.

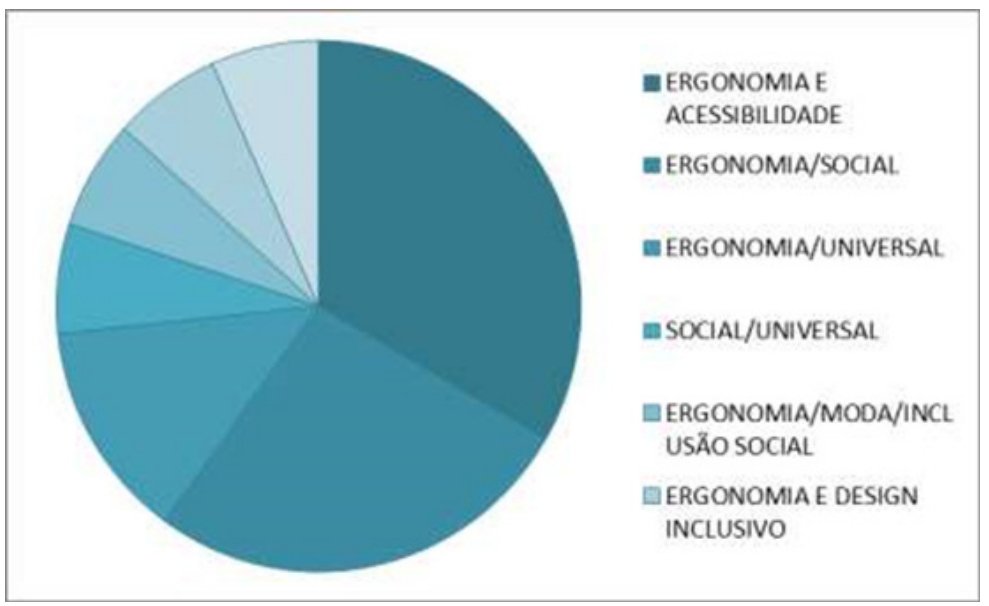

Fonte: Elaborado pelo autor, com base na pesquisa realizada.

Houve também IES em Design com matrizes curriculares que se enquadram nos critérios da pesquisa e que tem disponíveis as ementas nos sites institucionais. As ementas disponíveis totalizaram 28 para a disciplina Ergonomia I e 9 para Ergonomia II. Já as demais disciplinas com ementa foram registradas apenas 1 
vez, sendo elas: ergonomia visual, estudos ergonômicos, ergonomia cognitiva, ergonomia informacional, ergonomia e interação humano-computador, ergonomia e vestuário, ergonomia do produto, acessibilidade e adaptabilidade, ergonomia e usabilidade, design sensorial, design de interação, interfaces digitais, antropometria e ergonomia, usabilidade.

O total de IES que disponibilizaram as ementas no site foi de 25 , sendo que a mesma IES disponibilizou ementas para cursos diferentes. Algumas das IES foram: Universidade Estadual de Londrina, Universidade Federal de Uberlândia, Fundação Universidade do Estado de Santa Catarina, Universidade Estadual de Maringá, Universidade Regional de Blumenau, entre outras. Conforme mostra o Gráfico 6, as principais palavras citadas nas ementas disponibilizadas nos cursos de Design, que são interessantes para o presente artigo foram, Usabilidade 12 repetições, seguida de Acessibilidade com 9, Desenho Universal com 4 e Design Inclusivo com 1.

Gráfico 6 - Principais palavras citadas nas ementas.

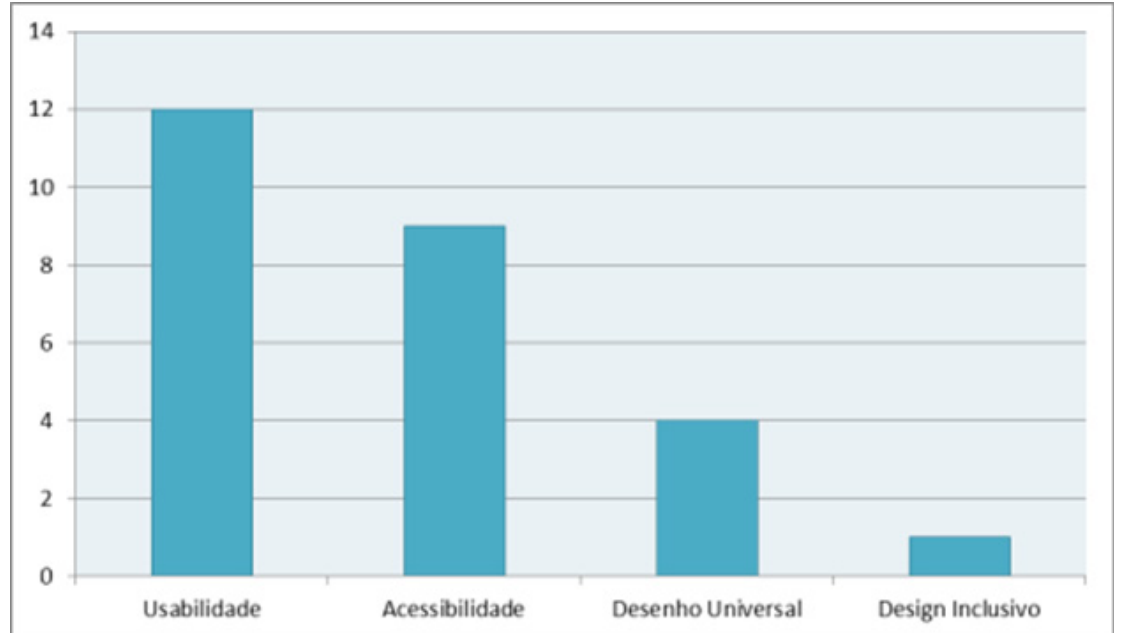

Fonte: Elaborado pelo autor, com base na pesquisa realizada. 
Com relação aos cursos de Pós-graduação Lato Sensu e Stricto Sensu também, realizaram-se, análises nos sites institucionais das IES. Assim, constatouse que 36 IES que participaram do ENADE 2012 na área de Design, possuem cursos com Especializações, Mestrados ou Doutorados com linhas de pesquisa relacionadas à inclusão social, acessibilidade, ergonomia, entre outros. Conforme o Gráfico 7, pode-se notar que $68 \%$ dos cursos de Pós-graduação com linhas na área de interesse são cursos de Especialização (28 cursos sobre o total de 36), 25\% são cursos de Mestrado (10 cursos sobre o total de 36) e 7\% são cursos de Doutorado (3 cursos sobre do total de 36 ).

Gráfico 7 - Pós-graduação nas IES.

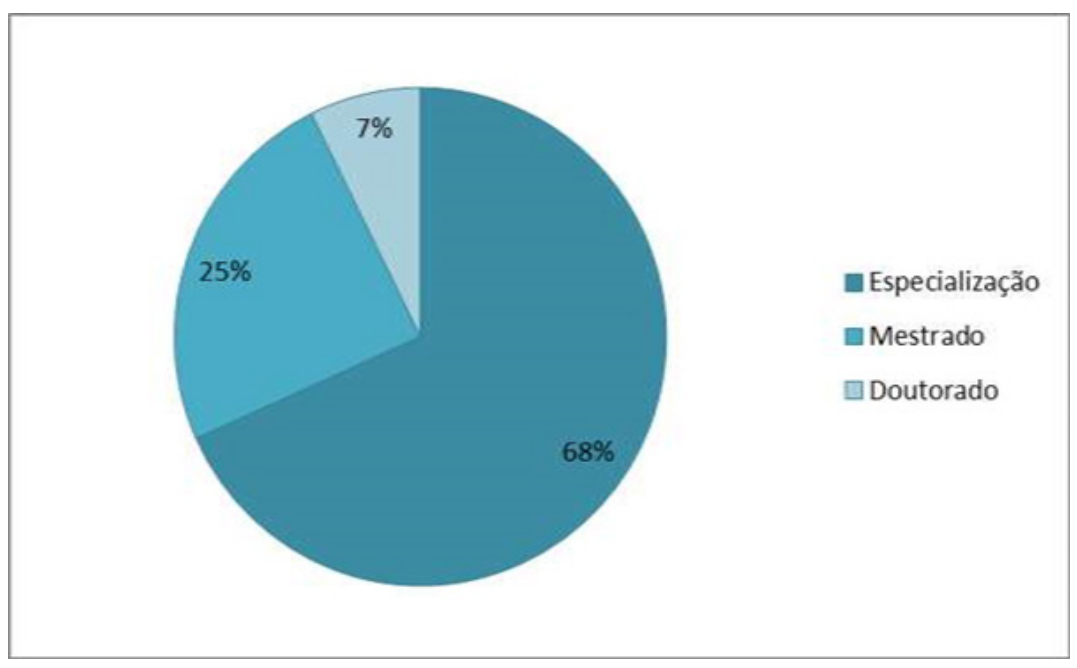

Fonte: Elaborado pelo autor, com base na pesquisa realizada. 
Gráfico 8 - Principais áreas de interesse nas Especializações das IES.

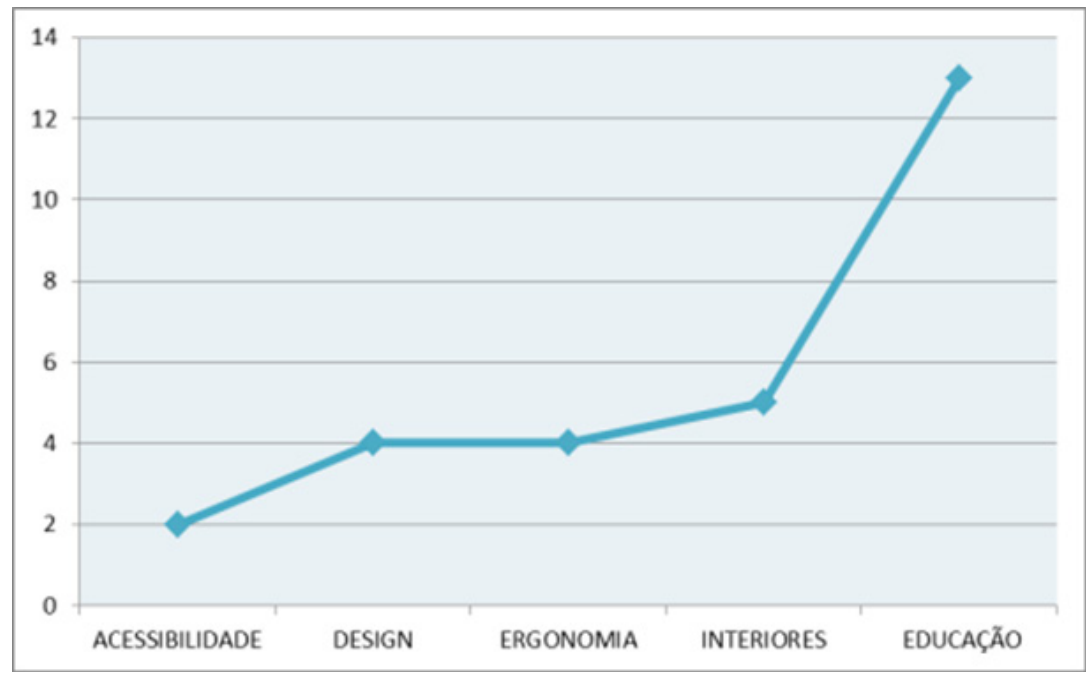

Fonte: Elaborado pelo autor, com base na pesquisa realizada.

As linhas temáticas de pesquisa nos 10 cursos de Mestrado analisados, que tem relação com a inclusão social, ergonomia ou acessibilidade, foram Design em 8 vezes, seguido de Educação com 1 e Fisioterapia com 1. Com relação ao Doutorado os 3 cursos encontrados tratam de linhas de pesquisa com área temática em Design. Já nos cursos de Especialização, como mostra o Gráfico 8, percebe-se que 13 dos 28 cursos tem relação com a área temática da Educação, 5 com Interiores, 4 com Ergonomia e também 4 com Design e 2 com Acessibilidade. 


\section{CONSIDERAÇÕES FINAIS}

No atual contexto social em que nos deparamos hoje, a inclusão social está sendo cada vez mais percebida pelas Instituições, pois, as mesmas começam a entender a importância de ter o conhecimento sobre essas questões, com o objetivo de auxiliar a comunidade e também proporcionar novas experiências práticas e reais com os estudantes.

Através dos dados encontrados nesta pesquisa e dos resultados analisados, pode-se obter um panorama geral sobre as Instituições de Ensino Superior em Design no Brasil, por meio dos dados obtidos pelo ENADE 2012. Com este estudo, verificou-se que o volume de disciplinas voltadas para a área da inclusão vem crescendo vagarosamente, em comparação com os anos anteriores, mas ainda é pouco trabalhada nos cursos de Design no Brasil.

Como objetivo a presente pesquisa pretendia responder o problema de pesquisa no qual tratava-se da caracterização do Ensino em Design através das matrizes curriculares e linhas de pesquisa propostas pelas IES em Design. $O$ problema de pesquisa foi respondido de forma geral, ao possibilitar a identificação das IES que participaram do ENADE 2012 e que possuem cursos de Design até o ano de 2016, propiciou a categorização das Habilitações dos cursos de Design, permitiu que fossem analisadas uma a uma as matrizes curriculares disponíveis nos sites institucionais proporcionando um agrupamento para posterior contagem das mesmas, também possibilitou o descobrimento das disciplinas que tem suas ementas livres para acesso nos sites e assim trazer um entendimento maior sobre o que as IES preocupam-se em ensinar os estudantes de Design e por fim também propiciou o saber sobre as linhas de pesquisa e áreas temáticas dos cursos de Pósgraduação das IES analisadas.

No que diz respeito à metodologia utilizada, este estudo pode contribuir para pesquisas futuras que poderão utilizar-se deste tipo de método para realizar

trabalhos de áreas correlacionadas ou diversas. Para um trabalho futuro sugere-se 
Projética, Londrina, v. 12, n. 1, p. 143-167, março 2021

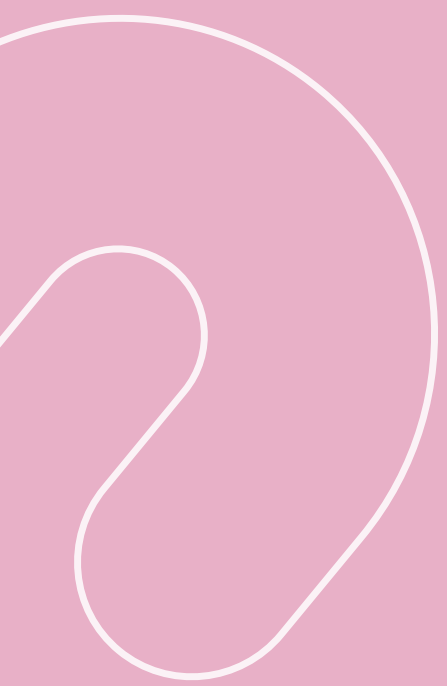

No atual contexto social em que nos deparamos hoje, a inclusão social está sendo cada vez mais percebida pelas Instituições, pois, as mesmas começam a entender a importância de ter o conhecimento sobre essas questões, com o objetivo de auxiliar a comunidade e também proporcionar novas experiências práticas e reais com os estudantes. 
uma análise com maior profundidade em outras bases de dados específicas das IES na área do design, como também na busca em trabalhos de conclusão de curso, dissertações e teses, de forma à complementar este estudo.

Por fim, este trabalho deseja propor discussões e/ou caminhos de pesquisas com a intenção de contribuir e fomentar estudos no meio acadêmico científico sobre os assuntos debatidos. A inclusão social pode ser trabalhada nos cursos de Design através do Design Universal e da Acessibilidade, sendo de extrema importância para a sociedade e para as pessoas com deficiências, pois, promovem o respeito e a integração dos mesmos de forma única. 
Projética, Londrina, v. 12, n. 1, p. 143-167, março 2021

\section{REFERÊNCIAS}

1. ANDRADE, Martha Sahade Araújo de; PACHECO, Marina Locatelli; FARIAS, Sandra Sâmara Pires. Pessoas com deficiência rumo ao processo de inclusão na educação superior. Revista Conquer, Barreiras, BA, v. 1, p. 1 -5, 2007.

2. BITTENCOURT, Leonardo Salazar; MUNIZ CORRÊA, Andreia Lopes; MELO, Juliana Duarte de; MORAES, Miguel Correia de; RODRIGUES, Raquel Faião. Acessibilidade e cidadania: barreiras arquitetônicas e exclusão social dos portadores de deficiências físicas. In: CONGRESSO BRASILEIRO DE EXTENSÃO UNIVERSITÁRIA, 2., 2004, Belo Horizonte, MG. Anais [...]. Belo Horizonte: UFMG, 2004. p. 1-7.

3. BRASIL. Lei $\mathrm{n}^{\circ} .10098$ de 19 de dezembro de 2000. Estabelece normas gerais e critérios básicos para a promoção da acessibilidade das pessoas portadoras de deficiência ou com mobilidade reduzida, e dá outras providências. Brasília, DF: Presidência da República, 2000.

4. CARLETTO, Ana Claudia, CAMBIAGHI, Silvana. Desenho universal: um conceito para todos. São Paulo: Instituto Mara Gabrilli, 2008.

5. COOK, Albert M.; HUSSEY, Susan M. Assistive technologies: principles and practices. Sant Louis, Missouri: Mosby - Year Book, 1995.

6. COUTO, Rita Maria de Souza. Escritos sobre ensino de design no Brasil. Rio de Janeiro: Rio Books, 2008. Disponível em: http://portal.inep.gov.br/enade. Acesso em: 13 jul. 2016.

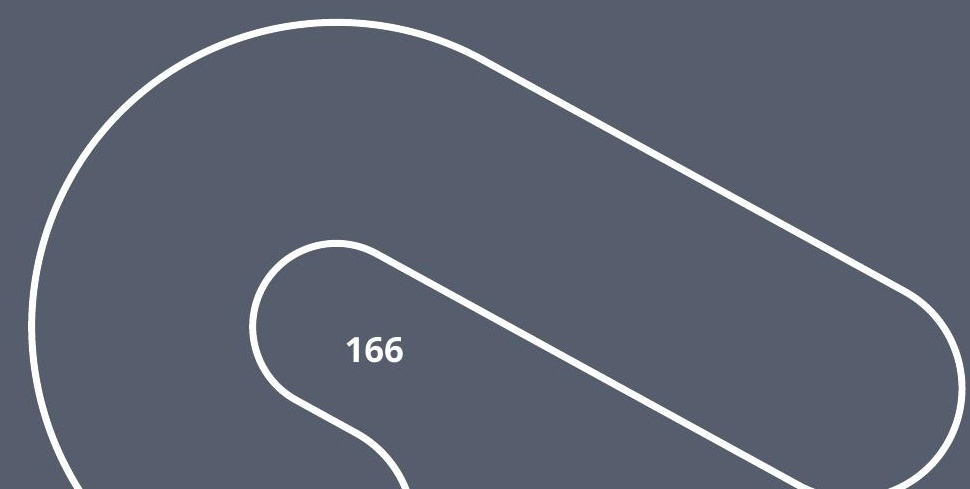


A inserção do design universal... institucionais

SURIS, B. S.; MEURER, H.; RIBEIRO, V. G.

7. GUIA sobre a lei brasileira da inclusão 13.146/15. Brasília, DF: Mara Gabrilli, 2015. Disponível em: http://www.planalto.gov.br/ccivil_03/leis/l10098.htm. Acesso em: 13 jul. 2016.

8. IIDA, Itiro. Ergonomia: projeto e produção. 2. ed. rev. e ampliada. São Paulo: Blucher, 2005.

9. INSTITUTO NACIONAL DE ESTUDOS E PESQUISAS EDUCACIONAIS ANÍSIO TEIXEIRA - INEP. Exame Nacional de Desempenho dos Estudantes - ENADE. Disponível em: https://www.gov.br/inep/pt-br/areas-de-atuacao/avaliacaoe-exames-educacionais/enade. Acesso em: 13 jul. 2016.

10. LAMÔNICA, Dionísia Aparecida Cusin; ARAÚJO-FILHO, Pedro; SIMOMELLI, Simone Berriel Joaquim; CAETANO, Vera Lygia Santos Butignoli; REGINA, Márcia Regina Rodrigues; REGIANI, Denise Maria. Acessibilidade em ambiente universitário: identificação de barreiras arquitetônicas no campus da USP de Bauru. Revista Brasileira de Educação Especial, Bauru, SP, v. 14, n. 2, p. 177-188, 2008.

11. PRODANOV, Cleber Cristiano; FREITAS, Ernani Cesar de. Metodologia do trabalho científico: métodos e técnicas da pesquisa e do trabalho acadêmico. 2. ed. Novo Hamburgo: Feevale, 2013.

12. SAMPAIO, Rosana Ferreira; MANCINI, Marisa Cotta. Estudos de revisão sistemática: um guia para síntese criteriosa da evidência científica. Revista Brasileira de Fisioterapia, São Carlos, v. 11, n. 1, p. 83-89, 2007.

13. SARTORETTO, Mara Lúcia Sartoretto; BERSCH, Rita. Assistiva. Tecnologia e Educação. 2014. Disponível em: http://www.assistiva.com.br/tassistiva.html. Acesso em: 23 dez. 2015. 